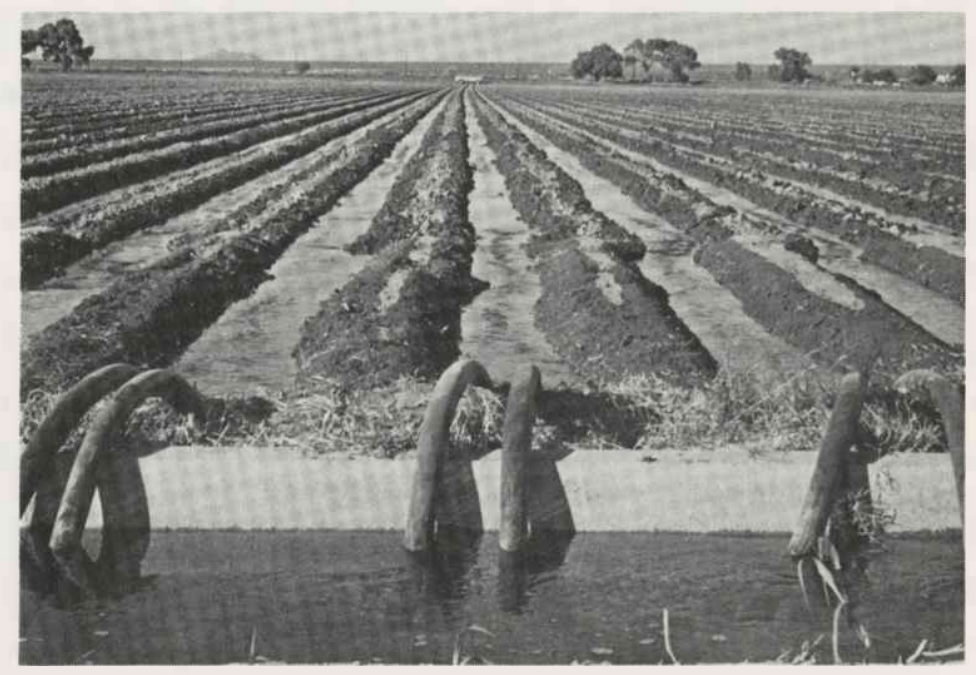

\title{
Challenges and Responses
}

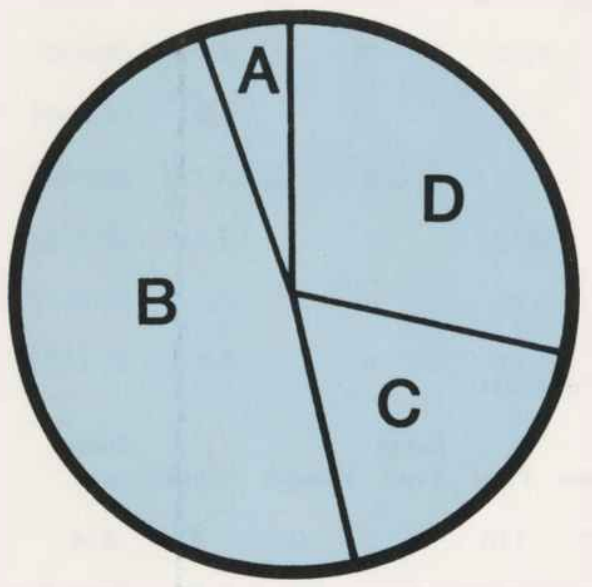

Figure 2. Arizona's water supply in thousands of acre-feet.
A. Natural Recharge 300
B. Overdraft 2,200

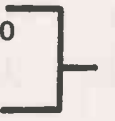
Groundwater 2,500
C. Colorado River 900
D. Other 1,400

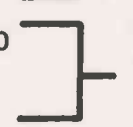
Surface water 2,300

Normalized 1970 conditions.

Total: $4,800,000$ acre-feet. An additional $3,500,000$ are diverted or pumped, but return to the water supply instead of being depleted by use.
Limits to amounts of water and good land challenge Arizona agriculture. The past and predictable growth of the state's population increase the demand for these resources. Energy costs are also pushing up the price for pumping groundwater.

Of the two, water is a more critical resource for our agriculture than land. For Arizona land to be good cropland, it needs a supply of irrigation water. However, high water costs are putting some irrigated cropland out of production, and urban growth is overrunning some of the remaining cropland that gets the less expensive irrigation from rivers and lakes, instead of from underground. Soil quality factors are also important.

Agriculture is adapting to the limits and costs of available water. The problems appear soluble by individual adoption of techniques already available or under development. The loss of prime cropland converted to other uses is a longer-range issue. It may require a collective approach, rather than individual efforts, to give due weight to society's present and future interests.

\section{The Problem: Water}

About 80 million acre-feet of precipitation fall on Arizona in an average year. (Each acre-foot equals 43,560 cubic feet.) Of that water, plus some that drains into the Colorado River from other states, about 3 million acre-feet are diverted from rivers and lakes for use by people in Arizona. In addition, almost 5 million acre-feet of water are pumped out of the ground each year. About a third of the water pumped or diverted flows or seeps back into the water supply. Actual depletion, based on 1970 conditions, is estimated at 4.8 million acre-feet. This includes 2.3 million acre-feet from surface water and 2.5 million from groundwater. The state's underground supplies of water are replenished naturally with only about 300,000 acre-feet a year, so roughly 2.2 million acre-feet of pumped groundwater are not replaced (see Figure 2).

We are overdrawing our groundwater account by about 2.2 million acre-feet annually. Consequently, underground water levels are 
dropping in many areas. Near Stanfield and Eloy, levels have dropped about 180 feet since 1940 . Water that is further underground is more expensive to pump out, and often higher in unwanted salt content. In several places, such as an area near Picacho, the ground itself is subsiding as water is sucked out from under it. Some evidence suggests the subsiding began even before local pumping began, though it has been greatly accelerated by the pumping.

To stop the overdraft on groundwater reserves, Arizona must reduce pumping by about 2.5 million acre-feet a year while the population continues to increase rapidly. Irrigated agriculture uses ninetenths of the water used in the state, counting both surface and groundwater. The other tenth goes to homes, mines, industries, electric power, and fish and wildlife uses (see Figure 3).

Room for improved efficiency exists for all types of water users. Phoenix residents, for example, use one-third more water per person per year than Tucson residents. However, the biggest share of the necessary reduction in water use will come from the biggest user, irrigated agriculture. Cutting back the amount of water pumped for irrigation will mean either less irrigated land or less water per acre.

Two attacks underway against the overdraft problem are the Central Arizona Project (CAP) and the 1980 Groundwater Management Act. CAP aims to substitute surface water from the Colorado River for some of the groundwater used. By current estimates, the project will deliver 1.5 million acre-feet in 1990, tapering off to 1.0 million acre feet by 2030 . The new groundwater law requires the management of pumping, with quantity restrictions phased in over the next 45 years in specified "Active Management Areas."

A more immediate factor fostering conservation in groundwater use is the high cost of pumping. Just in the past five years, escalating energy costs have pushed pumping costs up 50 to 65 percent in major groundwater irrigation areas of Maricopa, Cochise and Pima counties. Long-term cost arrangements in Pinal County electric districts have held costs per foot of lift steadier in that county, but many of those arrangements will be renegotiated by 1990 .

In addition to the energy-price factor, dropping water levels also raise pumping costs. Two consecutive years with above-average precipitation have actually raised water levels in some areas, especially near the Gila River at Painted Rock Reservoir and downstream. In most pumping areas, though, and over the longer time-frame, groundwater levels are dropping.

For many farmers who use groundwater, water costs amount to half or more of their total variable costs. Figure 4 shows the recent increases in this proportion of costs for some crops.

Prices received for major crops have increased in recent years, too, offsetting some of the water-cost inflation. Nevertheless, the higher pumping costs have raised the incentive for efficiency in irrigation: each acre-foot that is not pumped because it is not needed represents more dollars saved than it used to. An acre-foot worth of new efficiency in irrigation does not, however, reduce groundwater overdraft by the same amount. Some of the water now lost in irrigating a field flows or seeps back to a surface or underground water supply. Thus, even substantial improvements in irrigation efficiency will not solve overdraft problems.

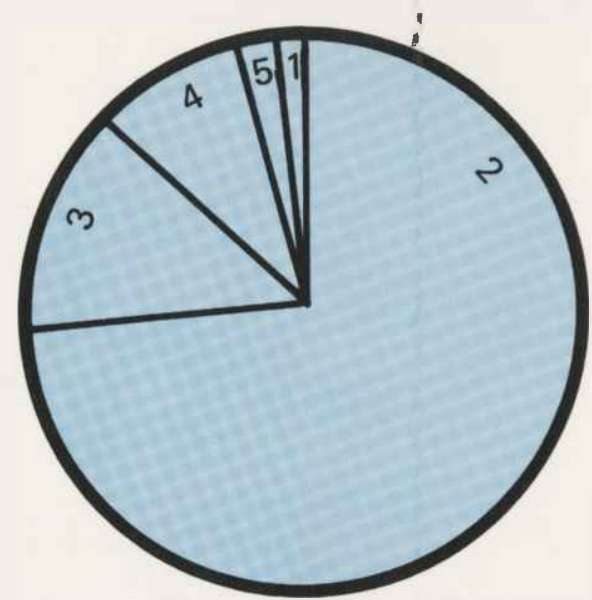

Figure 3. Annual water use by Arizona's major water users (in thousands of acrefeet of water depleted).

1. Steam-Electric Power 20

2. Irrigation 4,294

3. Municipal \& Industrial 329

4. Mining 131

5. Fish \& Wildlife 40

Normalized 1970 conditions. Source: Arizona Water Commission.

1975

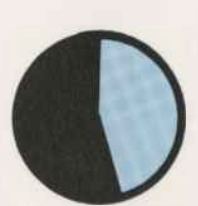

$54 \%$

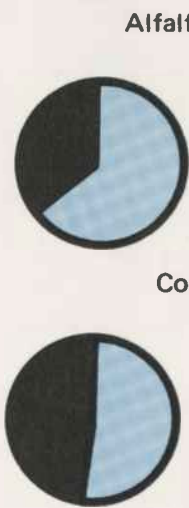

Alfalfa Hay
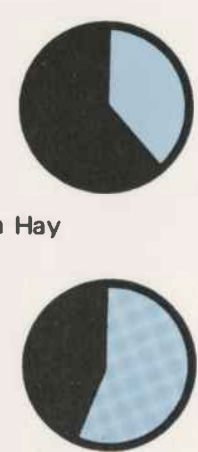

Cotton

$46 \%$

Wheat

$58 \%$

Figure 4. Water as a percentage of total variable production costs of selected Arizona crops, 1975 and 1980.

Figures are based on variable water costs (\$44.54 for energy and $\$ 5.40$ for repairs per acre foot) and total variable costs of production for selected crops in the Queen Creek area. 


\section{The Problems: Land}

Nationwide, an average of four square miles of prime farmland have been converted to non-agricultural uses each day for more than a decade. In Arizona, the total amount of cropland has stayed close to 1.2 million acres for 30 years. The stability of the total, however, masks local patterns of change. Between 1967 and 1977, an average of 32,000 acres per year of Arizona agricultural land were converted to urban, built-up, rural transportation or open-water uses. Ten thousand of these 32,000 acres per year were prime farmland before conversion. While land in some areas has changed from cropland to other uses, however, new cropland has been claimed from the desert in other areas.

Some previously farmed areas, especially in Pinal County, have been idled because rising costs for water and other production factors have made farming uneconomical in those spots. This type of change is reversible, should future market conditions make agricultural use of the land attractive again.

Other losses of farmland are less reversible. In Pima County, more than 10,000 acres of formerly irrigated farmland near Tucson have been retired from production because the city bought the land for the water rights that come with it. This sort of land-use change is determined not by whether crops can be raised economically on the irrigated land, but by whether urban users or agricultural users are willing to pay more for the water rights. The 1980 Groundwater Management Act provides for the purchase and retirement of some irrigated lands starting in 2006, and for other types of water-right transfers to non-agricultural uses starting immediately.

Even more permanent are the changes of land from farm use to residential and industrial uses as Arizona's cities expand. In a single 10-month sample period eight years ago, 3,650 acres in a one-millionacre study area in and around Phoenix changed from farm use to urban use. More than 80 percent of the lost farmland had Class One soils, the top rating from the U.S. Soil Conservation Service. Another study included one million acres that ringed the Phoenix urban area in 1970. More than 65,000 of the 375,000 acres of agricultural land in that area in 1970 had changed to residential and other urban uses by 1978 (see Figure 5). Some prime cropland that was northwest of the Tucson urban area a decade ago has also become part of the city.

As described in the preceding article, new agricultural areas have been opened or expanded as farmland around the cities disappears. Many of the new areas, though, especially in western Maricopa County and in Cochise and Graham counties, depend on groundwater rather than on the less-expensive and usually less-salty surface water available to much of the land that has gone out of farm use near Phoenix. In Yuma County, most of the new agricultural land gets irrigation water from Colorado River projects.

The land around the cities is in an assortment of low-intensity uses, including parks, rangeland, mines and undeveloped desert, as well as cropland that varies in quality. Arizona cities are going to keep growing rapidly. The challenge is to weigh society's long-term interests into the decisions about which parcels of low-intensity land will be converted to urban uses. Poorly planned urban growth may bequeath to future generations an undesirable quantity, quality or distribution of farmland. The public interest in a potential for increased agricultural 


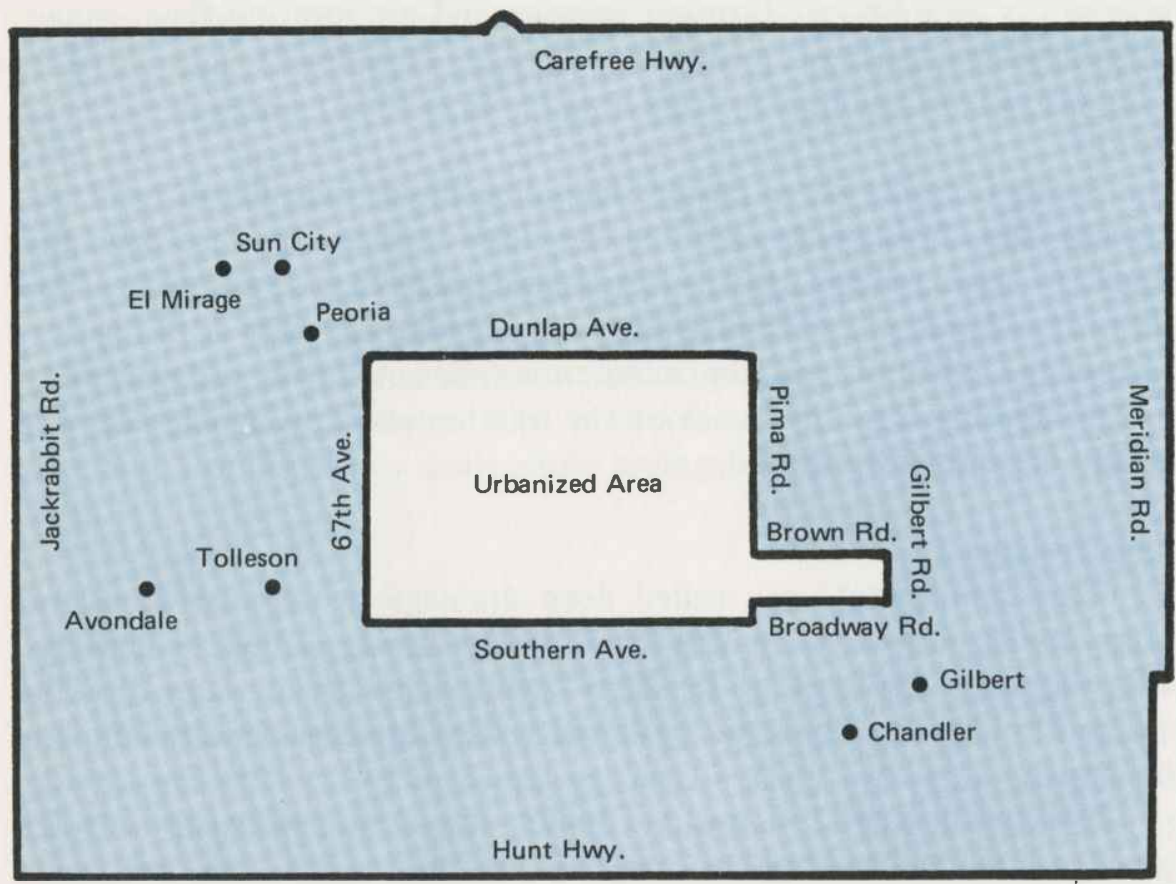

Figure 5. Generalized 1,600-square-mile rural-urban fringe study area in Maricopa County (shaded area) in which 18 percent of the agricultural land in 1970 had been converted for residential and urban uses by 1978. From "A Directed Graph Approach to Rural-Urban Fringeland Conversion," by George F. Hepner, 1979.

production in the future is not built into current systems for buying and selling land around cities.

\section{Possible Responses: Water}

Efficiency in irrigation means applying only as much water as a crop really needs. Efforts to achieve that in Arizona date back hundreds of years, but have recently expanded in urgency and scope. Irrigation as we now know it developed in an era when energy costs were relatively modest. Interest in water-use efficiency was mostly academic, since paying for an extra irrigation or two made more economic sense than risking a yield-reducing water stress. The new energy costs and overdraft problem are now restoring water to a major place in economic calculations. Yields per unit of water applied and per unit of energy are as meaningful as yields per acre. The successful irrigator in Arizona's future will quote yields per acre-foot as readily as he now quotes yields per acre.

Optimum efficiency in irrigation will require management tailored to the soil and climatic characteristics of each field, rather than treatment as though all were identical. This management will require more precise measurement of the characteristics of each acre. Fortunately, the tools for this job already exist.

Plants use water, plus carbon dioxide from the air, to make simple carbohydrates, which are both the fuel and a basic component for growth of the plant. Four other things can happen to water that is applied to a field: runoff, deep seepage, evaporation from the soil and transpiration from the plant. Each of these four components of the "field water budget" offers opportunity for improving irrigation efficiency. Even before the irrigation water reaches the field, though, 
Table 6

A Comparison of Improved Irrigation Systems

Side-roll Sprinkler System

Efficiency: $\quad 70-80$ percent

Capital Requirement: $\$ 200-\$ 300$ per acre

Labor Requirement: moderate

Energy Requirement: moderate to high

Soil Requirement: no special conditions

Restrictions: best for shorter crops (alfalfa \& grain), poor in windy conditions

\section{Center Pivot}

Efficiency: $\quad 70-80$ percent

Capital Requirement:

Labor Requirement:

Energy Requirement:

Soil Requirement:

Restrictions:

Machine Operations:

$\$ 275-\$ 325$ per acre

low

moderate to high

sandy or high-infiltration-rate

special practices required for trees and vines; less affected by wind than other types of sprinklers

some problem due to circular field

(continued on page 13) some water can be lost through seepage and evaporation from canals and reservoirs.

\section{Runoff}

Runoff results when water is applied faster than it can infiltrate into the soil. This component of the field water budget has been the easiest to measure and usually the easiest to reduce or eliminate. The capture and reuse of runoff water from the tail end of irrigation furrows is a common practice on Arizona fields. Adoption of such practices to eliminate runoff losses on the fraction of farms which have not already done so is warranted.

\section{Deep Seepage}

This component, also called deep drainage or percolation, is the water which moves down out of the root zone, pulled by gravity. It is the most difficult of the four components to measure directly but also holds the opportunity for the largest increases in efficiency in the future.

Non-uniform infiltration is a major reason for seepage losses. In furrow or flood irrigation, the amount of water that soaks into any part of the field depends on the length of time that water is ponded on the surface at that spot. In order for high spots to get enough water, low spots must get too much water. In a poorly leveled field, this can mean as much as 40 percent too much water is applied overall. Even on precisely leveled fields, though, variations in the permeability of the soil in different parts of the field can cause non-uniform infiltration of water. Soil permeability can vary several-fold within a single field.

The use of laser equipment to level fields precisely is spreading rapidly. This technique solves the problem of high and low spots on zero-slope fields. Conventional land grading usually is adequate for sloped fields, where tolerances are greater. No amount of leveling can overcome the problem of permeability differences, however. To reduce that problem, control of water infiltration must be removed from the soil surface and incorporated into the irrigation system. Sprinkler, trickle and related systems can apply the desired quantity of water more uniformly over the field. Trickle systems can raise irrigation efficiency to 80 to 90 percent. Sprinklers, or well-graded furrow systems that catch and re-use runoff water, can achieve 75 to 80 percent efficiency. Fifty to 70 percent is estimated for a poorly graded furrow or flood system without a re-use feature and with irrigation practices geared to convenience of labor. The more efficient systems, however, are also more expensive initial investments (see Table 6).

Since virtually all irrigation waters in the West contain salts, some deep seepage is essential to prevent salt build-up in the root zone. In most cases, leaching with about one-tenth of the applied water, once a year, is sufficient to maintain a favorable salt balance. Again, uniformity of application is important, since the portions of a field most in need of leaching are those that normally get the least irrigation water.

Excessive preplant irrigation and poor irrigation scheduling can also cause excess deep seepage. Efficient irrigators can assess the amount of water the soil in each field can hold against the pull of gravity and then apply as nearly that amount as possible. A flow meter at the pump can aid in the accuracy of application. Neutron moisture 
probes, available to farmers through irrigation consultants, can detect deep seepage. Checking each field periodically with a neutron probe helps refine estimates of how much water the soil can hold in the root zone.

For efficiency, irrigation scheduling must be extremely flexible. Irrigation by the calendar will eventually become obsolete. Irrigation for 24-hour periods in order to save labor will also disappear. Farmers may monitor their soil moisture, estimate the time and amount of their next irrigation from weather data, and apply precisely the amount required. Automatic systems with pre-programmed micro-processors to start and stop the flow may allow savings in pump energy-use and in labor.

\section{Evaporation}

Runoff and deep drainage usually find their way back to the surface or groundwater system, but evaporation from soil and transpiration from plants are lost into the atmosphere. These last two components are difficult to measure separately. They are often considered together as "consumptive use" or "evapotranspiration." Great strides in understanding and accurately estimating them have been made in the past 20 years.

Evaporation from the soil is greatest when the soil is wettest. Some modest savings in water loss are possible by reducing the percentage of soil wetted, as with trickle irrigation. Trickle systems, however, keep the wet portion of the surface wet longer than other systems do. Shading the surface with a mulch or with early vegetative cover can reduce evaporation losses. Narrower row spacings can result in an earlier complete vegetative cover. As water-use efficiency becomes a more important factor in comparison with the advantages of standardized farm machinery, experimentation with row spacing and plant density is increasing. Precise timing of preplant irrigations may cut evaporation losses, too. If a preplant irrigation is applied too long before planting, much water may evaporate or seep away before the seedlings can use it.

\section{Transpiration}

Transpiration gets the most attention of the four components in the field water budget. However, much of the optimism about increasing irrigation efficiency by reducing transpiration losses is based on misconceptions. Reducing transpiration from a given plant reduces the plant's total dry-matter yield proportionally. Most of the water transpired from a plant exits through small openings, called stomates, in the leaf. The stomates must open up to take in carbon dioxide from the atmosphere for photosynthesis, and this permits the transpiration of water vapor.

The water-use efficiency for a crop plant is the amount of yield the plant produces with a given amount of water. When yield is considered as the total dry-matter production of the plant, the efficiency depends on two factors: 1) the difference between the water-vapor pressure in the leaf and the water-vapor pressure in the adjacent air, and 2) an efficiency factor for the type of plant. This basic plant factor is the same for all plants with the same type of photosynthesis. Crop plants fall into two groups, with the tropical grasses such as corn and sorghum being about twice as efficient as the others.

Table 6 (continued)

Trickle Irrigation System

Field Preparation: install pipes, emitters and porous tubes

Efficiency: $\quad$ 80-90 percent

Capital Requirement:

Labor Requirement:

Energy Requirement: $\$ 650$ and up per acre

Soil Requirement: Restrictions:

low to high

low to moderate

no special conditions

crop must have high value to support debt service

Machinery Operations:

may have considerable problems due to tubes

Improved Furrow Irrigation System

Field Preparation: grade to uniform slope, install tailwater recovery system

Efficiency:

Capital Requirement:

Labor Requirement:

Energy Requirement:

Soil Requirement:

uniform, with moderate slopes and low-tomoderate infiltration

\section{Level Basin System}

Field Preparation: laser-level and border, install water turnou ts in concrete ditches

$$
\text { Efficiency: }
$$

Capital Requirement:

Labor Requirement:

Energy Requirement:

Soil Requirement:
80 percent

$\$ 400-\$ 900$ per acre

low

low

uniform soil of zero slope with moderateto-low infiltration 


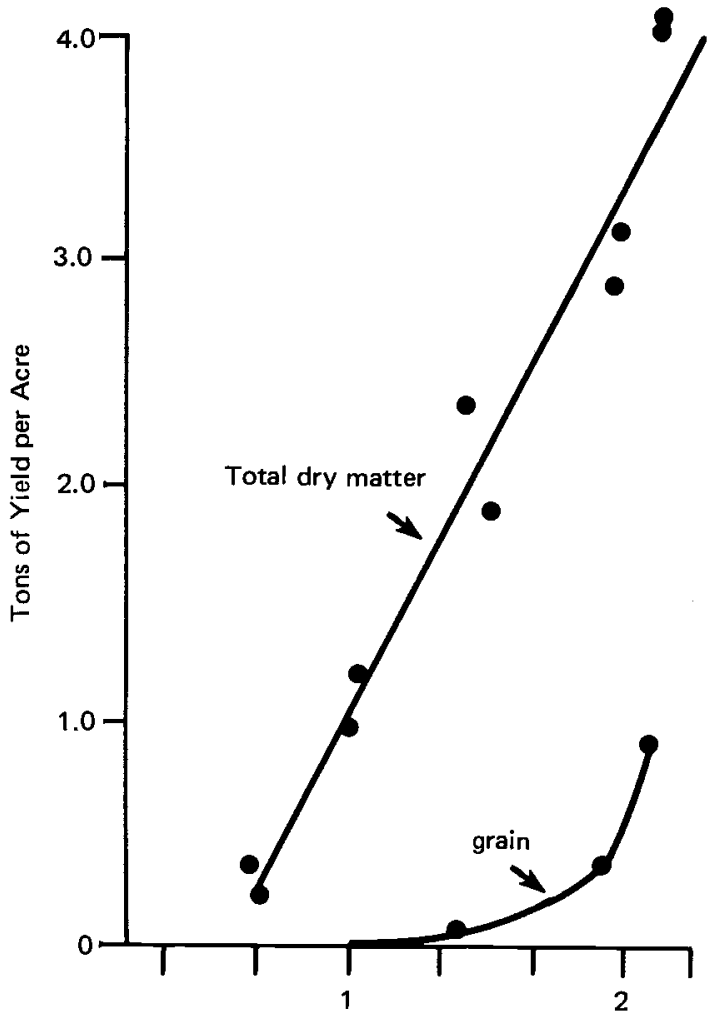

Acre-feet of Evaporation and Transpiration

Figure 6. Production of corn grain and dry-matter with different levels of evapotranspiration, Yuma 1975.
For plants with the same type of photosynthesis, growing at the same place and time, less transpiration means less dry-matter production. Except for a few species that can open their stomates at night and store carbon dioxide until daylight, desert plants seem to use water for dry-matter production no more efficiently than traditional crop plants. Instead, they are able to grow more slowly, or grow only when water becomes available. It is unlikely that plant breeders, at least in the near future, will be able to produce plants for which the basic efficiency factor is substantially higher. Improvements can be expected to continue, however, in manipulating the distribution of dry matter among the various parts of the plant. For most crops, one part of the plant, such as the seed, the leaf, or the root, holds the chief economic value of the plant.

The difference in water-vapor pressure between the leaf and air can also be manipulated to reduce transpiration losses. The warmer the leaf, the higher the vapor pressure in the leaf. The drier the air, the lower the vapor pressure in the air. Thus, transpiration rates are high in warm, dry Arizona. Growing crops during the cooler seasons instead of summer can minimize transpiration losses here. In midsummer, a daily water use of 0.4 inch is not unreasonable for a fullcover crop. In mid-winter, it might use 0.15 inch per day.

\section{Putting Theory to Work}

Figure 6 illustrates the tie between evapotranspiration and yield. This information from a Yuma experiment includes both evaporation and transpiration. It gives dry-matter and grain yields for corn, but represents a pattern that holds for other crops as well. Between about eight inches and 26 inches of water use, each additional inch resulted in an increase of about 800 pounds per acre of dry matter produced. These numbers, but not the linear pattern, would be different for other climates or times of year. The upper end of the graph approaches the limit of evapotranspiration. Beyond that, additional water becomes runoff or deep drainage and does not increase yield.

Other factors, such as infertile soil, environmental stress or disease, may limit yield before the point of maximum transpiration is reached. For water-use efficiency, irrigation should be cut back when factors other than water limit growth. In such a case, soil water measurements are the best guide for irrigation management.

Figure 6 shows a second important point. Water use is closely related to dry matter yield. With alfalfa, the farmer cares about total dry matter, including the root system, but with many other crops, he is interested in just part of the plant, such as the grain or fiber. This harvestable yield is not always related simply to transpiration. Water stress often affects one part of a plant differently than other parts. For example, with decreasing water use in the 24 to 26 -inch range, the grain yield in Figure 8 drops more sharply than the total dry-matter yield. Sugar beets are an opposite case: water stress may reduce total dry-matter yield without hurting sugar yield, unless the stress is extreme. Stressing cotton just prior to harvest reduces yields somewhat, but it is not possible to predict just how much yield reduction results from each inch of water withheld. Timing of water, as well as amount, can be important. Water stress at a crucial stage such as flowering or fruiting may be more damaging than stress at other times. 
Consumptive Use vs. Water Duty

Consumptive water use for a crop is the amount of water evaporated or transpired during the growing season for that crop, when it is grown for maximum harvestable yield. The consumptive-use estimate presumes that plants are not subjected to water stress unless that is a deliberate and normal field practice for the crop. Table 7 gives representative consumptive-use amounts for some Arizona crops.

The new Groundwater Act requires the director of the State Water Resources Department to determine the "irrigation water duty" for farms. The duty is the amount of water reasonably required to irrigate crops historically grown on the farm. The water duty is not the same as consumptive use for crops grown on the farm. It is premature to speculate exactly how water duties will be set, but reasonable to expect that the considerations involved will include all four components in the field water budget discussed above: runoff, deep drainage, evaporation and transpiration. Once the water duty is set, the grower can use these same factors in determining how to use his limited water most effectively.

The Groundwater Act establishes five management periods for Active Management Areas. During the first, 1980-1990, water duties will be based on assumptions that lined ditches, tailwater pump-back systems, land leveling and efficient application practices will be used. The law does not, however, require a change from flood irrigation to drip or sprinkle systems. For the second management period, 19902000 , the water duties will assume "maximum conservation," taking into account the costs of efficient systems. Practices that maximize deep percolation and evaporation losses through uniform application will be encouraged by the lowered water duties. Crops historically grown on a given farm will still be permitted there in the third management period, 2000-2010, when practices will be similar to those in the second but more stringent.

Some irrigators may find that pumping costs dictate even more water conservation than that mandated by law. An acre-foot of water pumped unnecessarily may make the difference between profit and loss when pumping costs approach $\$ 100$ per acre foot. Growers will also be using the flexibility the law gives each irrigator to bank or borrow up to half of each year's water duty.

The law requires installation of a water-measuring device on each well pumping 35 or more gallons per minute in Active Management Areas and Irrigation Non-Expansion Areas. This responsibility may seem onerous to irrigators and will take some care to ensure that each gauge measures accurately, but careful measurement of the water applied to each field is the necessary first step in full mangement of water. Only when the grower knows, for his own farm, how much water is consumptively used and how much is lost to deep drainage can he maximize his yield per unit of water. The Arizona farmer of the future will keep water accounts as carefully as he now keeps financial accounts.

It is apparent that the amount of Arizona land in urban uses will continue to increase, and that barriers to groundwater pumping will make establishment of new irrigated areas increasingly difficult after the first years of the Central Arizona Project. Given these conditions, should public policy encourage the preservation of specific areas of top-quality cropland?
Table 7

Some Reported Consumptive Use Data for Arizona Crops*

$\begin{array}{lc}\text { Crop } & \begin{array}{c}\text { Seasonal water } \\ \text { use (inches) }\end{array} \\ \text { Cotton } & 41 \\ \text { Barley } & 25 \\ \text { Cantaloupe } & 19 \\ \text { Sugar Beets } & 43 \\ \text { Potatoes } & 24 \\ \text { Wheat } & 23 \\ \text { Sorghum } & 25 \\ \text { Bermuda Lawn } & 44 \\ \quad \text { (April-October) } & \\ \text { Alfalfa } & 74 \\ \text { Grapefruit } & 48\end{array}$

* Consumptive water use figures from Mesa, except grapefruits, from Yuma. 
Level, well-drained land accessible to transportation networks is highly desirable for both cropland and urban development. Concern about how land should be allocated between these two types of use focuses on the difference between immediate advantages and future advantages.

Any public program to influence land-use decisions works against the assumption that free-market forces allocate land in a way that maximizes overall net benefits. A weakness of the land market working by itself is that it does not give full weight to the interests of future generations. Changes from cropland to city land are practically irreversible, so such changes limit the land-use possibilities available in the future. An allocation that gives maximum social net benefits now may leave future generations fewer acres, or lower quality, of cropland than would be most beneficial at that time.

Future interests can be protected by a public policy to conserve prime farmland through government action. But such action should only follow a realistic assessment of the free market's inefficiencies and inequities in allocating land compared to those possible under the proposed government action.

Various methods for conserving prime farmland are being tried in different states. In 1967, Arizona began a program of preferential tax assessment to protect land in low-intensity uses from property tax increases due to nearby urban growth. Farmland is taxed on the basis of its value in agricultural production instead of its market value as a potential site for housing or other high-intensity use. This approach has apparently not controlled the conversion of prime farmland to urban uses. It still allows sale of farmland to developers at market price. Careful empirical studies found that an even stronger California law, which prevents market-price sales of land taxed as agricultural, has been ineffective in slowing conversion.

New York has adopted an agricultural-district system under which a group of local farmland owners with combined property of more than 500 acres can agree to restrict use of their land to agriculture in return for property tax relief. Hawaii has developed statewide zoning. All land is zoned into four categories: urban, rural, agricultural and conservation. Connecticut is pioneering a system that compensates farmland owners for foregoing rights to develop or sell their land for more intensive uses. The government takes away development rights for the farmland it wants conserved and gives the farm owner development rights to other land where development is allowed. Anyone who wants to develop that land for intensive use must own the development rights as well as the land.

The fairness and effectiveness of these various programs are being evaluated in the states involved. University of Arizona agricultural economists are carefully studying land-use trends around Arizona cities. These types of information, coupled with extensive public participation, can help realize land-use allocations that are efficient and equitable for present and future generations. 